\title{
A EMERGÊNCIA DE UM MERCADO EDUCATIVO NO PLANEAMENTO DA REDE ESCOLAR: DE UMA REGULAÇÃO PELA OFERTA A UMA REGULAÇÃO PELA PROCURA
}

\author{
JoÃo BARROSO* \\ SOFIA VISEU*
}

(...) nem o Estado, nem a sociedade civil constituem um contexto adequado para o exercício de uma cidadania activa e democrática, através da qual seja alcançada a justiça social. A reafirmação dos direitos dos cidadãos em educação parece exigir o desenvolvimento de uma nova esfera pública, algures entre o Estado e a sociedade civil mercantilizada, em que novas formas de associação colectiva possam ser desenvolvidas. O desafio reside em saber como sair de um processo de decisão atomizado, para o assumir de uma responsabilidade colectiva em educação, mas sem recriar um sistema de planificação supencentralizado (...).

(Geoff Whitty, 2002, p. 20)

RESUMO: O presente artigo visa a reflectir sobre a emergência de lógicas de mercado na regulação da oferta educativa, nomeadamente a partir de processos formais e informais de "escolha da escola" pelos alunos e suas famílias. Com base numa investigação em curso no Centro de Estudos da Escola da Faculdade de Psicologia e de Ciências da Educação, da Universidade de Lisboa, foi possível identificar "desvios" às normas da "carta escolar" (que estabelece, em Portugal, a obrigatoriedade da frequência de uma determinada escola em função

* Professor catedrático e coordenador do Centro de Estudos da Escola da Faculdade de Psicologia e de Ciências da Educação, da Universidade de Lisboa. E-mail: jbamoso@fpce.ul.pt

* Investigadora do Centro de Estudos da Escola da Faculdade de Psicologia e de Ciências da Educação, da Universidade de Lisboa. E-mail: sofia.viseu@fpce.ul.pt

Educ. Soc., Campinas, vol. 24, n. 84, p. 897-921, setembro 2003

Disponível em <http://www.cedes.unicamp.br> 
da residência dos alunos). Esses desvios configuram uma evolução, no planeamento da rede escolar, de "uma regulação pela oferta" para "uma regulação pela procura" e põem em evidência o aparecimento de novos espaços de interdependência/concomência entre as escolas, com visível efeito sobre o modo como é (ou não) garantida a igualdade de oportunidades.

Palavras-chave: "Carta escolar". Escolha da escola. Mercado educativo. Igualdade de oportunidades.

\title{
THE EMERGENCE OF AN EDUCATIONAL MARKET \\ IN THE SCHOOL SYSTEM PLANNING: FROM A REGULATORY SUPPLY TO A REGULATORY DEMAND
}

\begin{abstract}
This paper discusses the emergence of market logics in the regulation of the educational offer and provision, through the free school choice of students and parents. Based on the results of a research project we are developing at the School Studies Centre of the Faculty of Psychology and Educational Sciences, University of Lisbon, we were able to describe and identify differences between the nules established by the "school map" (in Portugal, students have to attend a given, determined by the place where they live) and reality. These differences seem to be the result of an evolution from a "regulatory supply" to a "regulatory demand" in the educational planning. Such differences are also good illustrations of the appearance of new areas of interdependence or competition between neighboring schools, and of how this may promote inequalities of opportunity.
\end{abstract}

Key words: "School map" (zoning). Free school choice. Educational market. Inequality of opportunity.

emergência de uma lógica de mercado nos processos de regulação das políticas públicas, com particular relevo na educação, constitui um fenómeno persistente que se desenvolve à escala global e que acompanha a crise do Estado-Providência e das suas formas de govemo, com especial incidência nas últimas duas décadas do século XX.

A coexistência, temporal e espacial, destes dois processos faz com que, muitas vezes, a mudança resuma-se a uma simples passagem (ou escolha) entre a regulação pelo Estado e a regulação pelo mercado. $\mathrm{Ou}$, como defendem algumas soluções mais simplistas para os actuais problemas das políticas educativas (baseados nos princípios da "economia mista"), que se tentem combater as "falhas" do Estado com o reforço do mercado, e as "falhas" do mercado com o reforço do Estado. Ora, como a experiência tem vindo a demonstrar, o problema não é de "mais" ou "menos" Estado, mas de um "outro" Esta- 
do. Além disso, as forças e os interesses em presença no processo de definição, coordenação e execução das políticas e acção educativas são muito mais amplos e diversificados do que a dicotomia Estado-mercado abrange.

Este facto é particularmente visível no processo de regulação da oferta educativa, como procuraremos demonstrar neste artigo. Na verdade, se a "livre-escolha" da escola é um dos instrumentos mais poderosos para a criação de um mercado educativo (em contraponto ao modelo da planificação centralizada pela "carta escolar"), o certo é que, como é visível no estudo aqui apresentado, há lógicas de interacção e escolha que não se inserem, necessariamente, num modelo concorrencial de mercado. Do mesmo modo, se a "carta escolar" foi justificada, num momento de expansão da escola pública, como forma de o Estado garantir uma oferta educativa homogénea e com igualdade de oportunidades de acesso, sabemos bem que isso nem sempre foi conseguido, e que este princípio de homogeneidade pôs em causa o respeito pela diversidade e especificidade dos alunos e de suas comunidades de origem. pontos:

De acordo com estes pressupostos o artigo desenvolve-se em três

Num primeiro ponto, faremos uma breve reflexão sobre a introdução de uma lógica de mercado em educação e do papel central que a "livre-escolha" da escola desempenha nesse processo.

Num segundo ponto, com base num estudo empírico realizado no âmbito de um projecto desenvolvido pelo Centro de Estudos da Escola, em colaboração com instituições de outros países europeus, ${ }^{1}$ apresentaremos e analisaremos dados que mostram a existência de fenómenos de escolha da escola pelas famílias dos alunos e de diferentes lógicas de acção por parte dos responsáveis pela direcção das escolas. Estes fenómenos estão na origem de uma hierarquia de posições relativas entre as escolas e configuram novos espaços de interdependência entre elas.

Finalmente, num terceiro ponto, apresentaremos as principais conclusões do estudo, com particular enfoque em dois pontos: a existência, em Portugal, e no que se refere ao planeamento da rede escolar, de uma transição entre uma regulação pela oferta e uma regulação pela procura; contributos que é possível extrair deste estudo, para a busca de processos alternativos de regulação das políticas educativas que não fiquem confinados à dicotomia Estado-mercado. 
Embora com cambiantes diferentes, verifica-se hoje uma crise global do modelo político-administrativo que serviu de referência ao desenvolvimento dos sistemas públicos de educação, no pós-guerra, quer nos países industrializados, quer nos países em vias de desenvolvimento. Essa crise está associada a fenómenos políticos e económicos mais vastos ("choque petrolífero", "crise do Estado-Providência", "emergência de políticas neoliberais", "globalização da economia" etc.) e tem dado lugar à adopção de diferentes medidas de reestruturação do sistema público de educação.

Estas medidas têm oscilado entre dois grandes extremos:

Um dos extremos, corresponde ao desenvolvimento de políticas altemativas globais que visam à substituição radical do modelo existente e dos princípios de "serviço público" em que se baseava. Essas políticas seguem um modelo neoliberal de "gestão centrada na escola" e assumem o objectivo expresso de criarem um "quase-mercado de educação" e de introduzirem a lógica económica que lhe está subjacente, na organização e no funcionamento da escola pública. Estão nesste caso, por exemplo, as medidas tomadas por govemos conservadores (entre as décadas de 1980 e 1990), no Reino Unido, nos Países Baixos, na Áustrália, na Nova Zelândia, bem como nos Estados Unidos da América (em particular com as administrações Reagan e Bush) e de certo modo, com carácter mais recente (a partir do início dos anos de 1990), com o movimento das charter schools. São de incluir, neste grupo, igualmente, muitos dos programas de ajuda ao desenvolvimento educativo nos países da América do Sul ou nos países do Centro e Leste da Europa, pertencentes ao antigo "bloco soviético", conduzidos e financiados por organismos intemacionais (em particular Banco Mundial) ou fundações (como a Fundação Soros), com os mesmos fins.

O outro extremo corresponde à adopção de iniciativas mais pontuais que, sendo, muitas vezes, do mesmo tipo de algumas das medidas anteriores, não assumem o objectivo expresso de substituir globalmente o modelo de serviço público existente, mas, sim, de introduzir ajustamentos ou melhorias no sistema, com a intenção de comigir aquilo que os seus promotores consideram ser os seus defeitos mais nefastos. E o que acontece, por exemplo, na Alemanha, Noruega, ou, particularmente, nos países da Europa do sul, como Portugal, Espanha, França, Itália. ${ }^{2}$ 
Apesar de existir um certo referencial comum no que respeita à adopção de determinadas orientações gerais (como sejam a descentralização, o reforço da autonomia das escolas, a participação local) e a adopção de medidas de carácter gestionánio inspiradas na modema gestão empresarial (ligadas à promoção da qualidade, da eficácia e da eficiência), as duas posições diferenciam-se substancialmente em função dos contextos políticos e dos antecedentes culturais e histónicos da administração pública, nos diferentes países.

Contudo, grande parte da literatura e dos estudos que têm sido produzidos neste domínio tem tomado como referência as reformas liberais do primeiro tipo, e tem havido uma tendência, por vezes abusiva ou não controlada criticamente, para transferir os resultados desses estudos e reflexões para outras realidades económicas e políticas muito diferentes, como são as dos países do segundo tipo.

Importa, por isso, ter em conta que aquilo que faz a especificidade das políticas neoliberais (nomeadamente nos países atrás referidos) não é a adopção do princípio da "descentralização" e do "reforço da autonomia da escola", nem a promoção de "novas" técnicas de gestão, mas, sim, a sua "combinação explosiva", com a livre-escolha, pelos pais, do estabelecimento de ensino frequentado pelos filhos e com o regime de concorrência entre as diversas escolas públicas, resultante da fómula de financiamento poraluno.

Na verdade, só perante a conjugação destes ingredientes é que se pode falar de uma política destinada à "construção de um mercado da educação". De acordo com essa política, a escola deveria ser "libertada" do Estado, genida como uma empresa, no quadro de um sistema de concomência gerado pela livre-escolha da escola pelos pais. Isso permitina a utilização de critérios de rentabilidade e eficácia baseados na "satisfação do consumidor", cujos efeitos incidem sobre o próprio sistema de alocação de recursos públicos (que os mais radicais defendem dever ser feito às famílias, pelo sistema de vouchers, e não directamente às escolas).

Importa, por isso, distinguir estes casos extremos, em que, como dizem Gaziel \& Warnet (1998), “o sistema escolar evolui dum serviço público conduzido por profissionais para um serviço de mercado regido por clientes" (p. 4), de outras situações híbridas, em que a "autonomia", a "gestão centrada na escola", "a escolha da escola" estão longe de ter esta definição tão explícita ou intencional, como é o caso de Portugal.

Isso não significa que no debate que antecede a adopção dessas medidas, ou em algumas opiniões expressas nos meios de comunica- 
ção social, bem como nas práticas de alguns actores, estas lógicas de mercado e suas propostas não estejam presentes. Contudo, elas não são majoritárias e acabam por ter de se confrontarem com outras lógicas, num processo micropolítico que faz a singularidade dessas políticas em cada país, como é o caso de Portugal.

\section{A "livre-escolha" da escola}

Um dos principais instrumentos para a criação de um mercado educativo tem consistido, como vimos, na possibilidade de escolha das escolas pelas famílias, quer no interior do serviço público, quer entre escolas públicas e privadas. A frequência das escolas continua a ser financiada pelo Estado (em maior ou menor grau, por meio de financiamento directo às famílias, ou às escolas, ou por meio de bolsas, taxas e isenções), mas os alunos deixam de estar sujeitos à obrigatoriedade de frequência das escolas da sua zona de residência ("sectorização"), como é próprio dos sistemas em que prevalece o planeamento da oferta educativa por intermédio da chamada "carta escolar".

O debate entre os defensores e opositores da "livre-escolha", na maior parte dos países onde foram ensaiadas experiências nesse sentido (Estados Unidos, Reino Unido, Nova Zelândia, Países Baixos, Chile, entre outros), baseia-se, normalmente, num conjunto de "crenças" que podem ser sintetizadas do seguinte modo. ${ }^{3}$

Para os defensores da "livre-escolha" (inspirados principalmente nas obras de Friedman, 1962, e Chubb \& Moe, 1990):

- A liberdade de escolha da escola é um direito parental.

- O sistema de administração directa da escola pelo Estado é, intrínseca e inevitavelmente, irresponsável, ineficiente, burocratizado, subordinado aos interesses dos funcionários e incapaz de se auto-reformar.

- A livre escolha da escola e a privatização da oferta educativa melhoram a qualidade das escolas e os seus resultados, ao introduzirem mecanismos de competitividade e de responsabilidade perante o consumidor, próprios do mercado.

Os opositores da "livre-escolha" contestam esta opção em função de três críticas principais:

- A liberdade de escolha da escola pelos pais reforça a estratificação económica, social e étnica entre as escolas, uma vez que 
os critérios de escolha utilizados pelos pais de estatuto socioeconómico mais elevado se baseiam mais na "qualidade" dos alunos do que na qualidade das aprendizagens e os pais das classes populares, ou de minorias étnicas, não têm informação, tempo e recursos para identificarem as "boas escolas" e, mesmo se tivessem, não tinham condições para porem em prática as suas opções. Ou seja, os comportamentos das famílias não são homogéneos, havendo diferenças claras de estratégias e resultados, conforme o seu estatuto social e a proximidade aos valores escolares pelo que, em vez de diversificar a oferta, 0 que esse tipo de regulação faz é hierarquizá-la.

- A competição entre as escolas induzida pelos mecanismos de escolha, mais do que produzir uma pressão para mudança ou melhoria das aprendizagens, faz com que as energias e os recursos da direcção das escolas se esgote em estratégias promocionais e de marketing para atrair os "melhores" alunos.

- As políticas de "escolha da escola" pelos pais dos alunos têm sido promovidas por sectores ligados essencialmente ao ensino privado (e confessional) e traduzem uma estratégia elitista na distribuição do serviço educativo que põe em causa o direito de todos os cidadãos a uma educação de qualidade nas suas comunidades de pertença.

Importa acrescentar que este debate é essencialmente ideológico e raramente apoiado em evidências empíricas. Contudo, apesar de a investigação existente ser insuficiente, baseada em experiências muito limitadas e não ter em conta a diversidade e complexidade das dimensões presentes no funcionamento do sistema educativo e nos seus resultados, é possível, no que se refere aos critérios de escolha da escola pelos pais dos alunos e aos seus efeitos, reunir alguns dados que relativizam os argumentos em presença. ${ }^{4} \mathrm{E}$ o que se pode ver, por exemplo, com as conclusões obtidas, por um de nós, mediante uma revisão da investigação realizada neste domínio (Barroso, 2003).

Por um lado, dispomos já de um número significativo de dados empíricos que mostram existirem nítidos efeitos de estratificação e segregação provocados pela "escolha da escola" pelos pais dos alunos. Para os defensores de uma escola elitista esse é um bom resultado e só prova que a regulação pelo mercado funciona de maneira eficaz como mecanismo de selecção social. Contudo, mesmo dentro das correntes liberais e conservadoras em que se encontram os maiores 
apoiantes da "livre-escolha" há alguns sectores que revelam preocupação por estes dados e tentam minimizar os seus "efeitos perversos". É o que se passa, por exemplo, nos Estados Unidos, com o sistema dos "cheques-ensino" (vouchers), em que sectores mais moderados tentam combater os defensores de um sistema totalmente desregulado (de acordo com as propostas de Friedman), por intermédio de um conjunto de medidas reguladoras, como por exemplo: os "cheques-ensino" só são concedidos às famílias de baixos rendimentos ou pertencentes a minorias étnicas, ou então é imposto um mecanismo de sorteio para seleccionar os candidatos; as escolas privadas são proibidas de cobrar propinas de um valor superior ao atribuído no "cheque" (ver a proposta do Center on Education Policy, 2000). Mas como é evidente, a existência destes efeitos de segregação como consequência da possibilidade de escolha da escola pelos pais dos alunos é um argumento suficiente para os seus opositores denunciarem o sistema, com base nos riscos que ele coloca à coesão social e ao ideal de bem comum, subjacentes ao serviço público de educação.

Por outro lado, dispomos igualmente de evidência empínica sobre a existência dos mesmos mecanismos de segregação escolar e social nos sistemas de ensino em que não funciona a "livre-escolha". Como as várias investigações confimmam, nos países onde existe a "carta escolar", com a consequente obrigação de os alunos frequentarem a escola da sua residência, a situação não é muito mais risonha, uma vez que o mesmo tipo de famílias acaba por conseguir "furar" o sistema, em função dos mesmos criténios. A polarização social, a hierarquização dos estabelecimentos, as desigualdades entre as escolas continuam a existir nos sistemas que utilizam a "carta escolar", embora de uma maneira mais encoberta. Um dos países europeus onde, até há alguns anos, vigorou um sistema rígido de obrigação de frequência da escola em função da residência (agora em vias de alguma flexibilização) - a França - conta hoje com um volume significativo de investigações que mostram existir fenómenos sistemáticos e consistentes de segregação gerados por processos "informais" de escolha da escola pelos pais ou de selecção dos alunos pelas escolas, muitas vezes associados a fenómenos de exclusão escolar e urbana (ver em particular Van Zanten, 1996, 2001, e Barthon \& Oberti, 2000). Estes processos informais são muito variados e dependem quer dos conhecimentos e do espírito de iniciativa dos pais dos alunos, quer do seu estatuto económico: obter uma demogação que permita frequentar um outro estabelecimento que não o da sua zona de residência; fomecer moradas falsas; "negociar" com o director da escola 
da sua preferência uma medida de excepção à "carta escolar"; mudar de residência para uma zona mais favorável; recomer ao ensino privado. Esses mesmos processos ocorrem em muitos outros países, nomeadamente nos Estados Unidos onde, de acondo com uma estimativa feita com base em estatísticas nacionais por Henig \& Sugarman (1999), calculase que os pais de cerca de um terço do total dos alunos que frequentam o ensino básico e secundánio escolheram o seu local de residência em função da escola em que queriam matricular os seus filhos (citado por Gill et al., 2001). ${ }^{5}$

\section{Da regulação pela oferta à regulação pela procura}

A existência de processos informais de escolha da escola pelos alunos (ou de "escolha" dos alunos pelas escolas), mesmo nos países onde vigora o sistema da "carta escolar", constitui um objecto de pesquisa importante para detectar (e interpretar) a emergência de "quase-mercados" e "novos" modos de regulação no domínio das políticas públicas de educação.

O estudo empírico ${ }^{6}$ que iremos apresentar de seguida, insere-se nesse objectivo e foi realizado em um concelho limítrofe de Lisboa que, de acordo com informações prévias, constitui uma unidade relativamente coerente para a observação dos fluxos de alunos e onde a oferta escolar em certos anos de escolaridade é superior à procura.

Este territónio urbano é composto por nove escolas: uma escola básica integrada; quatro escolas básicas com os $2^{0}$ e $3^{\circ}$ ciclos de escolaridade; três escolas secundárias com o 30 ciclo de escolaridade; e, finalmente, uma escola secundánia. ${ }^{7}$

A transição do 9ำ ano para o $10^{\circ}$ ano de escolaridade foi seleccionada como o momento decisivo para a observação dos fluxos de alunos por três motivos centrais. Em primeiro lugar, trata-se de um momento em que os alunos das cinco escolas básicas do temitónio, que tencionam prosseguir estudos de nível secundánio, têm de mudar de escola. Em segundo lugar, esse momento de transição comesponde a uma alteração nos critérios da "carta escolar" para a distribuição de alunos pelas escolas (da morada de residência para o curso e agrupamento que o aluno deseja frequentar). Finalmente, em terceiro lugar, esse é também um momento de selecção no sistema educativo, pois comesponde à conclusão da escolanidade obrigatónia, estando a inscrição no ensino secundánio associada ao reforço de estratégias escolares para o acesso ao ensino supenior. 
A metodologia seguida para o estudo dos fluxos escolares dos alunos foi composta por duas fases. Numa primeira fase, houve a necessidade de identificar e descrever os fluxos escolares dos alunos entre as escolas do território. O enfoque atribuído a este momento de transição implicou um design de investigação do tipo extensivo e descritivo, com a produção de dois questionários dirigidos aos alunos. O primeiro questionário foi aplicado aos alunos do 90 ano de escolaridade das escolas em estudo no ano lectivo 2001/2002, com o objectivo de conhecer as suas expectativas e desejos quanto a escola, curso e agrupamento a frequentar no $10^{\circ}$ ano de escolaridade, tendo sido devolvidos 517 questionários, o que corresponde a $81 \%$ do universo. O segundo questionário foi lançado no início do ano lectivo seguinte, 2002/2003, aos alunos que frequentam o $10^{\circ}$ ano de escolaridade nas escolas com ensino secundánio, com o objectivo de comparar as suas expectativas à saída do 90 ano com a sua situação escolar, tendo sido obtidas 584 respostas, o que corresponde a $80,3 \%$ do universo.

Os questionários continham questões para a caracterização social e económica dos alunos (nacionalidade, profissão e habilitações académicas dos pais... ), para a descrição do percurso escolar (repetições ao longo da escolaridade, escolas frequentadas... ) e para saber se a escola em que se encontravam correspondia, ou não, àquela que deveriam frequentar de acordo com os critérios da "carta escolar" (residência, local de trabalho dos pais...).

Numa segunda fase, o objectivo foi compreender e interpretar a configuração dos fluxos observados em função dos fenómenos de interdependência e das "lógicas de acção" das direcções das escolas, tendo envolvido, sobretudo, a recolha de dados de natureza qualitativa. Por um lado, a recolha documental de "projectos educativos", planos e relatórios de actividades, jornais escolares, folhetos, enfim, um conjunto de documentação escrita e produzida pelos actores escolares. Por outro lado, a recolha, por meio de entrevista, da opinião e perspectiva dos actores envolvidos nestas dinâmicas. Foram realizadas três entrevistas por escola: uma ao presidente do conselho executivo, ${ }^{8}$ outra ao presidente da associação de pais e encarregados de educação ou seu representante e, finalmente, uma entrevista a um professor. No total das 9 escolas foram realizadas 28 entrevistas. Esses dados permitiram identificar e analisar diferentes lógicas de acção (extemas e intemas) desenvolvidas pelos responsáveis pela gestão das escolas no 
sentido de contribuírem para a criação, manutenção ou correcção da sua posição relativa no seu teritório de pertença.

\section{A regulação pela oferta}

Em Portugal, de um ponto de vista formal-legal, a afectação dos alunos a uma determinada escola pública faz-se segundo regras gerais e não existe um sistema institucionalizado de escolha de alunos ou de escolas. No ensino básico obrigatório (do 1ํa ao 9o ano de escolaridade) as escolas são obrigadas a aceitar os alunos que residem (ou cujos pais trabalham) na sua zona geográfica de influência. No ensino secundário a afectação é mais flexível, sendo o critério dominante a escolha do curso e das opções. A única limitação a este princípio geral é o número de vagas existente em cada ano e ciclo, acordado nas "reuniões da rede" com os serviços desconcentrados do Ministério da Educação, em função das instalações e dos recursos docentes disponíveis. Geralmente, cada escola assegura a continuidade dos alunos durante o ciclo de estudos em que se matriculou inicialmente, pelo que, a haver selecção, ela só se efectua na passagem de ciclo: nas EB I (escolas que asseguram os três ciclos do ensino básico), na passagem do $1^{\underline{0}}$ para o $2^{\underline{0}}$ ciclo e do $2^{\underline{0}}$ ciclo para o $3^{\circ}$; nas EB 23, na passagem do $2^{\underline{0}}$ para o $3^{\mathrm{o}}$ ciclo; nas secundánias com $3^{0}$ ciclo do ensino básico, na passagem do 3 o ciclo para 0 ensino secundário. № caso de a procura ser superior à oferta, as escolas devem dar prioridade aos alunos mais novos ou que tenham irmãos a frequentar a escola, desde que obedeçam aos criténios de residência.

De um modo geral, esse princípio é assumido pelas escolas, embora sejam conhecidas diferentes modalidades informais para, pontualmente, contornar essa obrigação. Quando numa determinada escola a procura é supenior à oferta, o controlo destas regras é teoricamente mais apertado, mas também é maior a pressão para pô-las em causa, quer por parte da escola, afastando alunos "menos desejáveis", quer por parte dos pais, arranjando "moradas falsas". Nessas situações, como o critério de prioridade é determinado pela idade mais baixa, isso significa que os alunos com pior percurso escolar (maior número de repetências) são mais facilmente deslocados para outra escola. Em contrapartida, se a procura é inferior à oferta, as escolas têm tendência a flexibilizar os critérios da "carta escolar" admitindo alunos de fora da sua zona de influência. 
Em síntese, podemos dizer que a gestão dos fluxos escolares dos alunos, em Portugal, continua a obedecer, no essencial, às regras de obrigação de frequência da escola pública em função do local de residência dos alunos ou do local de trabalho dos pais, subjacentes ao planeamento da oferta educativa pela "carta escolar". Essas regras foram concebidas para fazer face ao planeamento da oferta escolar num período de expansão da frequência de alunos e perderam muito do seu sentido original num período de retracção dessa frequência, como o que se verifica actualmente em Portugal e como os dados obtidos no presente estudo claramente o demonstram.

Na verdade, durante o peńodo de expansão, caracterizado por uma forte procura (aumento da escolaridade obrigatória, democratização do acesso ao ensino) e por um défice de equipamentos e de vagas, os responsáveis pelos estabelecimentos de ensino podiam desenvolver estratégias "clandestinas" de selecção de alunos e, embora não haja investigação produzida sobre este fenómeno, há evidências claras (a partir de testemunhos diversos) de que tal acontecia. Contudo, a partir do momento em que, como hoje acontece em muitas localidades, a oferta de vagas excede a procura, começa-se a assistir ao fenómeno inverso, isto é, são os alunos e suas famúlias que desenvolvem estratégias (igualmente "clandestinas", ou pelo menos informais) de selecção das escolas.

\section{Aregulação pela procura}

Os resultados do questionário lançado aos alunos do 90 ano de escolaridade evidenciaram que apenas $59,2 \%$ dos alunos evocaram no boletim de matrícula pelo menos um dos critérios da "carta escolar" para fundamentar a sua escolha, o que significa que, no nível dos desejos e das expectativas, existe um desvio quanto aos critérios dessa carta. Esses desvios estão ilustrados na figura seguinte, na qual se comparam as preferências dos alunos que frequentavam o 9o ano em escolas básicas e o fluxo que seria de esperar de acordo com os critérios da "carta escolar". A cheio são assinaladas as porcentagens de alunos que escolhem uma escola secundária de acordo com os criténios da "carta escolar". A tracejado são indicadas as porcentagens de alunos que escolhem uma escola secundária sem atender aos criténios dessa carta (por exemplo, $11,4 \%$ dos alunos da EB I A preferem a escola secundária da sua área de influência, a ES A, mas 68,6\% dos alunos preferem a ES B, que não está abrangida pelos critérios da "carta es- 
colar"). Note-se que não estão assinalados todos os fluxos relativos a cada escola, mas apenas os que são mais pertinentes para o estudo.

\section{Figura 1}

(As preferências dos alunos e os critérios da carta escolar)

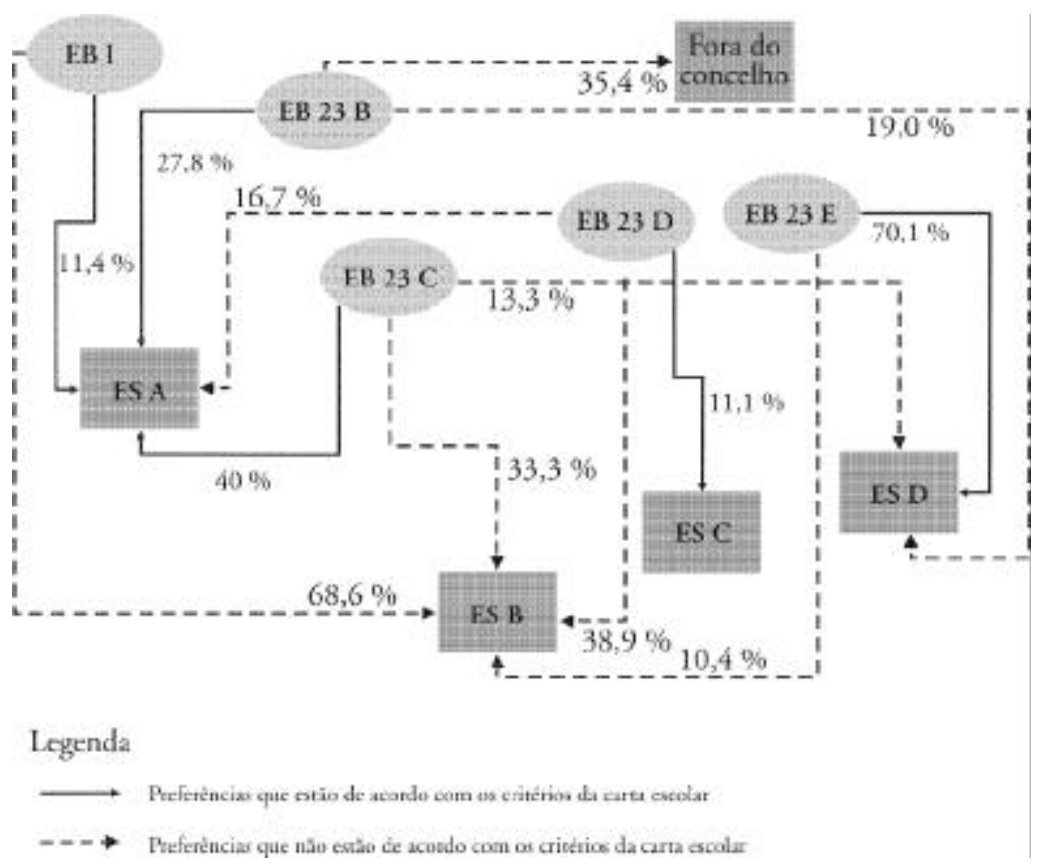

Estes dados foram reforçados pela análise dos resultados do questionário lançado aos alunos do 10ํano de escolaridade. Por um lado, 92,0\% dos alunos estão matriculados na escola escolhida como primeira opção. Por outro lado, apenas 58,2\% dos alunos inquiridos estão a frequentar uma escola secundária compatível com a utilização de um dos critérios da "carta escolar".

Com base nos dados obtidos (nos questionánios, nas entrevistas e na análise documental) foi possível proceder a um ensaio de construção de uma tipologia que permitisse distribuir as escolas em função da posição relativa que ocupam num mesmo espaço de interdependência/ concorrência. 
A tipologia foi construída tendo em conta duas dimensões de análise: a atractividade da escola, em termos de públicos escolares, e a sua mobilização, pedagógica e/ou organizacional.

Em relação à atractividade da escola foram considerados dois tipos de dados. Em primeiro lugar, a análise do fluxo escolar dos alunos que evidenciou, como vimos, escolas mais ou menos atractivas para as famílias e os alunos. Em segundo lugar, a evolução do número de alunos ao longo dos anos, assim como a composição e as caractenísticas da população escolar.

Em relação à mobilização, entendeu-se considerar o conjunto de medidas desenvolvidas pela gestão para melhorar o funcionamento geral da escola, com particular enfoque no domínio pedagógico, para promovera sua imagem junto da população local, e para garantira coesão ou consistência das políticas seguidas no combate às desigualdades.

O cruzamento dessas duas dimensões permitiu situar as escolas umas em relação às outras, pela análise das suas características.

\section{Figura 2}

(Tipologia das escolas)

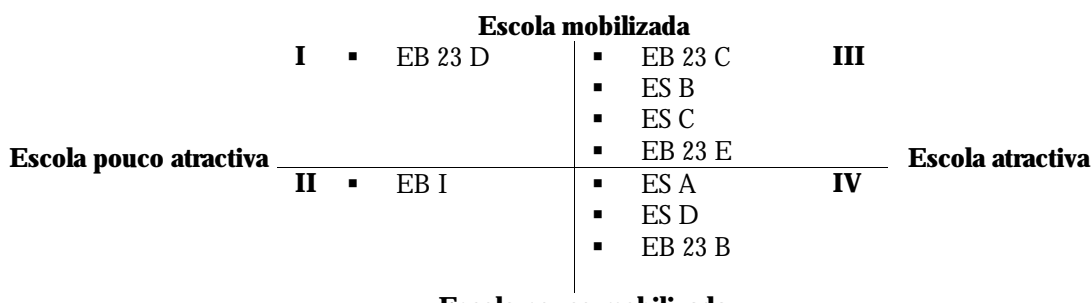

Escola pouco mobilizada

A figura evidencia diferenças entre as escolas no que toca à sua atractividade e à sua mobilização, sendo necessária a apresentação mais detalhada de cada um dos quadrantes, assim como das escolas que os ocupam.

I - Escolas pouco atractivasmasmobilizadas: A posição ocupada pela escola EB 23 D merece, desde já, uma justificação mais detalhada. Por um lado, a escola foi, durante muito tempo, pouco atractiva para as classes médias e altas residentes na sua área de influência por ser frequentada por alunos de classes sociais baixas, moradores num grande baimo clandestino e degradado. Apesar das caracteństicas da po- 
pulação escolar, a escola surgiu sempre como mobilizada pedagogicamente para receber esses alunos e procurou, se não resolver, pelo menos minimizar os seus problemas. Actualmente, com a extinção do bairro degradado, no quadro de uma política de realojamento, a escola apresenta-se como mais atractiva, sobretudo no $2^{\underline{0}}$ ciclo de escolaridade, ainda que sofra de uma imagem negativa que tende a esbater-se. A direç̧ão continua voluntariosa em melhorar as condições da escola.

II - Escolaspouco atractivase pouco mobilizadas: A EB I é a única escola do território que surge, em simultâneo, como pouco atractiva e pouco mobilizada. A escola tem apenas seis anos de existência e funciona num bairro degradado, habitado sobretudo por imigrantes e seus descendentes, nomeadamente das ex-colónias portuguesas. As características do bairmo reflectem-se nas características da população escolar e, aos olhos da restante população da freguesia, a escola surge como pouco atractiva pela má imagem pública que lhe é atribuída. A escola foi ainda considerada pouco mobilizada e a relação dos professores foi descrita como a mais difícil e conflituosa.

III - Escolas atractivas e mobilizadas: Neste quadrante se situam quatro escolas que foram identificadas como atractivas e, simultaneamente, mobilizadas. Contudo, a razão dessa atractividade e o tipo de mobilização são distintos entre as quatro escolas, sendo visíveis maiores diferenças no nível da ESB e da EB 23 C. No caso da escola secundária, essa atractividade é dada pela elevada procura dos alunos, nomeadamente dos alunos residentes fora da sua área de influência, $\mathrm{e}$ pela sua mobilização pedagógica, com o desenvolvimento de vários projectos que visam à integração dos alunos, pela diversificação da oferta escolar. Já no caso da escola básica, a atractividade assume, pelo contrário, um carácter mais selectivo de alunos; a elevada procura da escola é explicada pela sua boa imagem pública, sobretudo junto das classes médias e altas. A mobilização foi considerada como elevada pelo facto de os professores parecerem empenhados em manter essa boa imagem, nomeadamente para o exterior.

IV - Escolasatractivasmaspouco mobilizadas: Finalmente, três das escolas do teritónio foram identificadas como atractivas e, contudo, pouco mobilizadas, ainda que existam diferenças importantes entre si. O caso da ESD será interessante pelo facto de ser uma das escolas do ensino secundánio com melhor imagem pública do temitónio, embora os dados recolhidos apontem para alguma falta de mobilização no nível pedagógico. A boa imagem está em grande medida associada ao facto de a escola funcionar num edifício novo, com boas infra-estruturas e equipamentos; 
a reduzida mobilização está associada à falta de um aproveitamento mais efectivo das condições e dos recursos existentes. Quera EB 23 B quer a ESA foram colocadas nesse quadrante pelo contraste existente com as restantes escolas do quadrante III. Por um lado, na EB 23 B foi detectada uma reduzida oferta escolar, nomeadamente no que se refere a actividades extracurniculares e na ESA, existência de maiores clivagens e diferentes grupos de interesses entre o corpo docente; estas características conferem às duas escolas uma menor mobilização. Por outro lado, a base de recrutamento das duas escolas está muito restringida às suas áreas de influência, apresentando-se como atractivas apenas junto da população residente nessas áreas.

\section{Lógicasdeaç̧ão}

Na segunda fase do estudo, como foi dito, a investigação tinha como principal objectivo identificar em que medida a autonomia relativa, consentida ou concedida no quadro dos novos modos de regulação, permitiu às direcções das escolas disporem de estratégias próprias neste domínio, constituindo por isso um elemento suplementar de distinção entre as escolas. Ou seja, tendo sido confimada a existência de "posições" diferentes entre as escolas, como resultado dos processos de composição dos seus públicos, pretendia-se agora identificar qual o contributo da acção (extema e intema) da direcção dessas escolas para a criação, manutenção ou comecção dessa posição.

Por meio da análise dos dados obtidos foram identificados, como mais relevantes, os seguintes espaços/situações de intervenção (externa e interna), em que mais se afirmam as estratégias dos responsáveis pela gestão das escolas no sentido de melhorarem a sua posição relativa no seu espaço de interdependência.

Quanto às "lógicas de aç̧ão" extema:

- As "reuniões da rede", de iniciativa e coordenadas pela administração desconcentrada do Ministério da Educação (Centro de Área Educativa), em que é definida a distribuição da oferta educativa numa determinada área escolar (distribuição do número de vagas de alunos, por escolas, anos de escolaridade e cursos).

- Relações informais com as escolas a montante (escolas com grau de ensino inferior que enviam alunos), a jusante (esco- 
las com grau de ensino superior para onde são enviados alunos) e paralelas (escolas com os mesmos graus de ensino).

- Iniciativas destinadas a resolver problemas de instalações ou de funcionamento que contam com o apoio de entidades exteriores (Administração Regional, Câmara Municipal, empresas, associações, serviços sociais, de saúde, de segurança, locais etc.) ou da própria associação de pais.

- Actividades específicas de promoção da imagem pública da escola com o sentido de a tornar mais atractiva junto de potenciais alunos.

Quanto às "lógicas de acção" intema, a tentativa da direcção das escolas de controlar a influência do ambiente extemo e de lidar com os fenómenos de segregação e desigualdade de oportunidades, tendo em vista melhorar a sua posição relativa no seu espaço de interdependência, passa, sobretudo, pelo seguinte tipo de intervenções:

- Controlo dos professores sobre os órgãos de gestão, em particular a Assembleia de Escola (órgão de representação da comunidade educativa, criado pela legislação de 1998).

- Visão "funcionalista" das relações escola/família dos alunos, mais centrada na necessidade de os pais (principalmente dos "piores" alunos) ajudarem a resolver os problemas da escola do que no exercício do direito parental de tutela da educação dos seus filhos.

- Realização de projectos e actividades extra-curriculares, com o fim de melhorar a prestação do serviço educativo, de os professores obterem uma realização profissional não satisfeita pelo modelo uniforme decidido centralmente e de adaptar (a maior parte das vezes, de maneira isolada e sectorial) as condições de funcionamento da escola às características dos alunos e do meio social de pertença.

- Introdução de critérios de selecção de alunos na organização de horários e turmas, sujeitos a um certo enviesamento étnico e social, com reflexos na equidade do serviço educativo e na igualdade de oportunidades.

A análise destas diferentes lógicas (tendo em conta a sua frequência, conteúdo e sentido estratégico) nos permitiu concluir que, na maioria dos casos, as escolas limitam-se a "sofrer" as influências do ambiente social e quando desenvolvem estratégias específicas, nesse 
domínio, elas são essencialmente defensivas ou adaptativas. Já no que se refere às relações com as outras escolas, raramente assistimos a fenómenos de concorrência na disputa pelos "melhores alunos", sendo mais comum a estratégia assente numa espécie de "jogo de empurra" no sentido de evitar ficar com os "alunos problemáticos" (para utilizar uma expressão frequente nas entrevistas), principalmente nas mudanças de ciclo.

Na verdade, não se pode dizer que as lógicas de acção extemas e intemas desenvolvidas pelos responsáveis da gestão das escolas sejam fortemente marcadas pela necessidade ou pelo desejo de melhorar a sua posição relativa, num eventual espaço de concorrência determinado pelo surgimento de fenómenos de escolha da escola.

É certo que as escolas (que foram objecto do presente estudo) tentam tirar partido da existência de espaços locais de regulação do fluxo de alunos para melhorarem as suas condições de oferta escolar, para evitarem alunos "problemáticos", para adquirirem mais recursos e promoverem iniciativas que aumentem a qualidade dos serviços prestados. Para isso utilizam as reuniões da rede, solicitam o apoio da Câmara Municipal, procuram captar a colaboração dos pais, desenvolvem projectos extra-curriculares, estabelecem relações com outras escolas etc. Contudo, a tónica dominante continua a ser a de promoção de um serviço público "universal" para todos os alunos e não a de se adaptarem à satisfação de diferentes interesses privados.

Essas escolas se mobilizam não por imperativos de concorrência e disputa de um mercado, mas pela sua maior ou menor sensibilidade e competência para: atenderem às características dos seus alunos; cumprirem as suas obrigações de serviço público educativo; $\mathrm{e}$ explorarem a sua capacidade de negociação e as suas margens de autonomia, quer nos espaços institucionais de regulação centralizada, quer nos espaços informais de regulação local.

Claro que essa mobilização acaba por ter um efeito de atracção sobre a procura, quer reforçando as características favoráveis do seu público escolar, quer minimizando os efeitos negativos de um público escolar menos favorecido. A atractividade é, por isso, mais uma consequência do que um móbil das "lógicas da acção".

\section{Conclusão}

O estudo empíico realizado, com base na descrição dos fluxos dos alunos, na passagem do 9o ano (termo da escolaridade obrigató- 
ria) para o $10^{\circ}$ ano (início do ensino secundário), veio mostrar que existe um desvio significativo entre o fluxo esperado (de acondo com os critérios da "carta escolar"), o fluxo que seria resultante das preferências manifestadas pelos alunos e o fluxo efectivamente ocorrido. Esse facto indicia, claramente, a existência de fenómenos de "escolha da escola" pelos alunos e suas famílias, variável em função das escolas de origem e de destino. Neste sentido, é possível apresentar de maneira sucinta as seguintes conclusões:

- As escolas são diferentemente atractivas e essa atractividade decorre fundamentalmente da composição social (e sobretudo étnica) do seu público escolar e do modo como as direcções das escolas lidam com essa situação.

- A diminuição do número de alunos e a existência de processos informais de escolha da escola explicam que se comece a assistir, na regulação dos fluxos escolares dos alunos, a uma progressiva passagem de uma "lógica da oferta" a uma "lógica da procura".

- O facto de a distribuição dos alunos pelas escolas começar a ser regulada pela procura induz o aparecimento de novos espaços de interdependência entre as escolas e entre estas e 0 territónio.

- Esses espaços de interdependência ainda não são marcados pela concorrência e pela "lógica do mercado" (como acontece em outros países onde a escolha é totalmente livre), embora tenham sido identificadas estratégias, por parte da direcção de algumas das escolas, no sentido de desenvolverem "vantagens competitivas" ("tumo único", "oferta de opções de maior prestígio", "guarda dos alunos após o peńodo escolar" etc.), tendo em vista reforçar ou melhorar a sua "posição relativa".

- A tónica dominante nas lógicas extemas e intemas desenvolvidas pela gestão das escolas continua a ser a do "serviço público" universal e igual para todos, mesmo se, na prática, ele apresenta deficiências e desigualdades importantes.

- Isto não impede que as escolas procurem tirar partido da existência de espaços formais ou informais de regulação local para melhorar as suas condições de oferta educativa e resolver os problemas que têm com "alguns" alunos.

- Daí que o principal factor distintivo entre as escolas (para além das caractenísticas sociais e étnicas do seu público escolar) seja 
a capacidade de mobilização da suas direcções, no sentido de desenvolverem iniciativas próprias para resolução dos seus problemas e melhoria das suas condições de funcionamento.

- Esta "mobilização" não é determinada por uma tentativa de alterar a posição relativa entre as escolas, mas parece ter um efectivo peso no seu grau de atractividade (em relação aos alunos e pais).

- Finalmente, ainda não é visível, nessas escolas, uma forte influência dos "novos" modos de regulação emergentes nas políticas educativas baseados numa lógica de mercado. Contudo, tendo em conta, por um lado, as orientações recentes do governo que vão no sentido de aumentarem o controlo político sobre as escolas e promoverem a lógica de mercado na regulação dos fluxos escolares e, por outro lado, a continuação da diminuição dos alunos, é provável que a situação se altere. A própria "luta pela sobrevivência" (por postos de trabalho e por recursos) pode induzir mudanças nas lógicas de acção que até agora só são visíveis, pontualmente, no discurso de um número reduzido de entrevistados.

\section{Em síntese}

Como se vê, nem o sistema da "livre-escolha" nem o sistema da "obrigação de frequentar a escola do local de residência" impedem que se verifiquem processos de segregação escolar com origem em desigualdades sociais. No primeiro caso, essa segregação decorre da própria natureza da oferta escolar: há escolas "melhores" e "piores" que concorrem entre si para atrair clientes e, claro, os mais "poderosos" acabam por vencer. No segundo caso, essa segregação decorre da própria natureza da procura: há escolas aparentemente iguais que são desigualmente atractivas, em função de critérios étnicos, religiosos, sociais, de rendimento escolar etc. que só os pais mais informados e mais agueridos são capazes de descobrir e mobilizar, em benefício dos projectos de vida que têm para os seus filhos.

Por isso, como dizem Meuret, Broccolichi \& Duru-Bellat, (2001, p. 235), "entre o sistema da carta escolar e a selva do mercado, podem existir múltiplos dispositivos de escolha controlada que podem revelar-se bastante menos desiguais". Ou então, como dizem Dubet \& Duru-Bellat (2000, p. 136), "mais do que impedir as famílias de fugir, mais valia dar-lhes boas razões para o não fazer". Isso passa por ga- 
rantir uma escola pública justa e de qualidade para todos, que tenha em conta as especificidades locais, promovendo uma política de discriminação positiva que comija as assimetrias económicas e sociais, fazendo da participação dos alunos, dos professores e dos pais um exercício permanente de cidadania.

Como tenho escrito, a propósito das questões da gestão local e da autonomia da escola, é preciso evitar reduzir o debate sobre as políticas educativas à falsa dicotomia entre a administração centralizada, planificada e hierarquizada, por um lado; o mercado, descentralizado, concorrencial e autónomo, por outro. A realidade é mais complexa do que este raciocínio pressupõe e existem outras alternativas na educação pública, entre o "centralismo estatal" e "a livre concorrência do mercado", entre "a fatal burocracia do sector público" e "o mito da gestão empresarial", entre "o súbdito" e o "cliente".

No caso presente, isso significa que a opção não pode estar limitada entre, por um lado, preservar a escola pública impedindo as famílias de fugirem dela e, por outro, aniquilar a escola pública com a criação artificial de um mercado educativo sustentado com dinheiro público. A solução passa, pelo contrário, por um reforço da dimensão cívica e comunitária da escola pública, restabelecendo um equilíbrio entre a função reguladora do Estado, a participação dos cidadãos e o profissionalismo dos professores, na construção de um "bem comum local" que é a educação das crianças e dos jovens. Por isso, em vez de "dar a cada escola o seu público" é preciso que cada escola se abra à "diversidade dos seus públicos", o que só é possível se for intransigente no reconhecimento dos seus direitos e se for solidária com as suas necessidades, interesses e anseios. Só assim é possível desenvolver uma nova concepção de cidadania que, como defende Whitty (2002, p. 20) "vise a criar a unidade sem negar a especificidade".

\section{Recebido em julho de 2003 eaprovado em agosto de 2003.}

\section{Notas}

1. Trata-se do Projecto Reguleducnetwork ("Changesin regulation modesand social production of inequalities in education systems: a European comparison"), subsidiado pela Comissão Europeia, no âmbito do programa "Improving the socio-economic knowledge base". O projecto abrange cinco países europeus (Bélgica francófona, França, Inglaterra, Hungria e Portugal) e tem como objectivos a comparação entre a evolução dos modos de regulação pública dos sistemas educativos nesses países, bem como a análise dos processos locais de produção de hierarquias entre estabelecimentos de ensino e de desigualdades. Este projec-

Educ. Soc., Campinas, vol. 24, n. 84, p. 897-921, setembro 2003 
to decorre até outubro de 2004 e os seus relatórios parcelares podem ser consultados na página web do Centro de Estudos da Escola: www.fpce.ul.pt| centros\ ceescola.

2. Para uma apreciação crítica das políticas de reforço da autonomia em alguns desses países do Continente Europeu consultar, entre outros: Munin (Org.), 1999 (para a situação na Alemanha); Bolivar, 1998 e 1999 (para a situação na Espanha); Derouet, 1998, e Derouet \& Dutercq, 1997 (para a situação em França); Martelli et al., 1999 (para a situação em Itália); Barroso, 1998, 2000 e 2002; Estêvão, 2002; Lima, 2000; Lima \& Afonso, 2002; Marques Cardoso, 2003 (para análise da situação em Portugal).

3. Para um desenvolvimento deste tema consultar: Barroso (2003). A "escolha da escola" como processo de regulação: integração ou selecção social. Em J. Barroso (Org.), A escola pública: regulação, desregulação, privatização. Porto: Edições ASA, p. 79-106 - donde foi extraído o essencial desta informação sobre a "livre-escolha".

4. Existe uma vasta literatura sobre esta matéria, muitas vezes condicionada pelos pressupostos dos seus autores em favor ou contra a "livre-escolha". Contudo, dispomos igualmente de muitas investigações independentes e cientificamente sustentadas que medem quantitativamente os efeitos de segregação em experiências em curso, particularmente nos Estados Unidos, Chile, Colômbia, Reino Unido, Nova Zelândia, Bélgica e Países Baixos. Para uma revisão dos resultados destas investigações consultar, em especial: Carnoy \& McEwan (2001); Ball, Bowe \& Gewirtz (1996); Gill et al. (2001); Levin (2001 e 2003); Schneider (2001); Schneider \& Buckley (2002); Witte (2001); Whitty, Power \& Halpin (1998); Zachary \& Vandenberghe (2002).

5. Os dados globais desta estimativa, mesmo que indicativos, são elucidativos do processo de escolha da escola, nesse país: $41 \%$ não exerceram qualquer tipo de escolha; $36 \%$ exerceram a escolha da escola por meio da selecção da zona onde iriam residir, $10 \%$ escolheram escolas privadas; $11 \%$ recorreram a mecanismos experimentais de escolha da escola existentes em diversos distritos escolares; $2 \%$ preferiram o ensino doméstico; $1 \%$ escolheu as charter schools (Gill et al., 2001, p. 118).

6. Este estudo se integra numa investigação mais vasta realizada no âmbito do Projecto Reguleducnetwork (ver nota 1) e o seu relatório (Barroso \& Viseu, 2003) encontra-se disponível no sítio do Centro de Estudos da Escola.

7. O sistema educativo não superior português é composto pelo ensino básico obrigatónio e pelo ensino secundánio. 0 ensino básico divide-se em três ciclos: o $1^{0}$ ciclo tem a duração de quatro anos ( $1^{\circ}, 2^{\circ}, 3$ e $4^{\circ}$ ano de escolaridade), o $2^{\underline{o}}$ ciclo de dois anos ( $5^{\circ}$ e $6^{\circ}$ ano) e o $3^{\circ}$

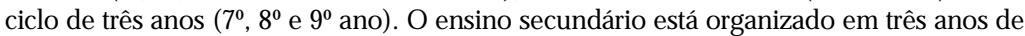
escolaridade: $10^{\circ}, 11^{\circ}$ e $12^{\circ}$ ano. As escolas podem assumir diferentes tipologias consoante os ciclos de escolaridade que nelas funcionam, com destaque para as configurações mais comuns: escolas básicas do $1^{\circ}$ ciclo, escolas básicas integradas (com $1^{\circ}, 2^{\circ}$ e $3^{\circ}$ ciclo) designadas por EB I, escolas com os $2^{\circ}$ e $3^{\circ}$ ciclos de escolaridade, designadas por EB 23, escolas secundánias com o 3 o ciclo de escolanidade e escolas onde só funciona o ensino secundánio.

8. A direcção de topo nas escolas é exercida pelo conselho executivo, constituído por uma equipa de professores escolhidos por uma assembleia eleitoral, na qual estão professores, funcionários não-docentes e representantes de pais e de alunos do secundário.

\title{
Referências bibliográficas
}

\author{
BAL, S.; BOWE, R; GEWIRTZ, S. School choice, social class and \\ distinction: the realization of social advantage in education. Journal of \\ Educational Policy, London, v. 11, n. 1, p. 89-112, 1996.
}


BARROSO, J. O reforço da autonomia das escolas e a flexibilização da gestão escolar em Portugal. In: FERREIRA, N. (Org.). Gestão democrática da educação: atuais tendências, novos desafios. São Paulo: Cortez, 1998. p. 11-32.

BARROSO, J. Autonomie et modes de régulation locale dans le système éducatif. Révue Française de Pedagogie, Paris, n. 130, p. 57-71, jan./mars 2000.

BARROSO, J. Gestão local da educação: entre o Estado e o mercado, a responsabilização colectiva. In: MACHADO, M.; FERREIRA, N. (Org.). Política egestão da educação: dois olhares. Rio de Janeiro: DP\&A ; ANPAE, 2002. p. 173-197.

BARROSO, J. A "escolha da escola" como processo de regulação: integração ou selecção social. In: BARROSO, J. (Org.). A escola pública: regulação, desregulação, privatização. Porto: ASA, 2003. p. 79-109.

BARROSO, J.; VISEU, S. Áreas deinterdependência local entre escolas: estudo de caso. (Relatório da equipa portuguesa do projecto Reguleducnetwork, WP 5. Lisboa: Centro de Estudos da Escola. Faculdade de Psicologia e de Ciências da Educação. Universidade de Lisboa). Disponível em: <www.fpce.ul.pt/centros/ceescola>. Acesso em: 2003.

BARTHON, C.; OBERTI, M. Ségrégation spatiale, évitement et choix des établissements. In: VAN ZANTEN, A. (Dir.). L'école, l'état des savoirs. Paris: La Découverte, 2000.

BOLIVAR, A. Usos políticos de la autonomia de los centros y obstáculos para su ejercicio. In: CONGRESO Interuniversitário de Organización de Instituciones Educativas, 5., 1998, Madrid. Actas del... Madrid: Universidades Complutense, UNED; Alcalá de Henares, 1998. p. 375-384.

BOLIVAR, A. Como mejorar loscentros educativos. Madrid: Síntesis, 1999.

CARNOY, M.; McEWAN, P. Privatization through vouchers in developing countries: the cases of Chile and Colombia. In: LEvin, $\mathrm{H}$. (Ed.). Privatizingeducation: can the marketplace deliver choice, efficiency, equity, and social cohesion?Boulder, Col.: Westview, 2001.

CENTER ON EDUCATION POLCY School vouchers. Washington, DC: Center on Education Policy, 2000.

CHUBB, J.; MOE, T. Politics, markets, and America's schools. Washington, DC: Brookings Institution, 1990. 
DEROUET, J.-L. Autonomie et responsabilité des établissements scolaires en France. Colóquio/Educação e Sociedade, Lisboa, n. 4, p. 19-31, 1998.

DEROUET, J.-L; DUTERCQ, Y. L'établissement scolaire: autonomie locale et service public. Paris: ESF, 1997.

DUBET, F.; DURU-BELIAT, M. L'hypocrisie scolaire: pour un collège enfin démocratique. Paris: Seuil, 2000.

ESTÊVÃO, C. Globalização, metáforas organizacionaisemudança educacional: dilemas e desafios. Porto: ASA, 2002.

FRIEDMAN, M. Capitalism and freedom. Chicago: University of Chicago, 1962.

GAZIEL, H.; WARNET, M. Le facteur qualité dansl'école del'an deux mille. Paris: PUF, 1998.

GIL, B. etal. Rhetoric versusreality: what we know and what we need to know about vouchers and charter schools. Santa Monica: Rand Education, 2001.

HENIG, J.; SUGARMAN, S. The nature and extent of school choice. In: SugARMAN, S.; KeMERER, F. (Org.). School choiceand social controversy: politics, policy and law. Washington, DC: Brookings Institution, 1999.

LEVIN, H. (Ed.). Privatizing education: can the marketplace deliver choice, efficiency, equity, and social cohesion. Boulder, Col.: Westview, 2001.

LEVIN, H. Os "cheques-ensino": um quadro de referência para a sua avaliação. In: BARROSO, J. (Org.). A escola pública: regulação, desregulação, privatização. Porto: ASA, 2003. p. 111-148.

LMA, L Administração escolar em Portugal: da revolução, da reforma e das decisões políticas pós-reformistas. In: CATANI, A.; O InvERA, R. (Org.). Reformaseducacionaisem Portugal eno Brasil. Belo Honizonte: Autêntica, 2000.

LMA, L; AFONSO , A. Reformas da educação pública: democratização, modemização, neoliberalismo. Porto: Afrontamento, 2002.

MARQUES CARDOSO, C. Do público ao privado: gestão racional e critérios de mercado, em Portugal e Inglaterra. In: BARRoso, J. (Org.). A escola pública: regulação, desregulação, privatização. Porto: ASA, 2003. 
MARTELU, S. et al. Autonomia: fondamenti, implicazioni, competenze. Brescia: La Scuola, 1999.

MEURET, D.; BROCCOLCHI, S.; DURU-BELAT, M. Autonomie et choix des établissements scolaires: finalités, modalités, effets. Les Cahiers de l'IREDU, Dijon, n. 62, 2001. Disponível em: <www.ubourgogne.fr/iredu/cahiers62.pdf>. Acesso em: fev. 2001.

MUNÍN, H. (Org.). La "autonomia" de la escuela: libertad y equidad? un recomido por la discusión alemana de los años noventa. Buenos Aires: AIQUE, 1999.

SCHNEIDER, M. Information and choice in educational privatization. In: LevIN, H. (Ed.). Privatizing education: can the marketplace deliver choice, efficiency, equity, and social cohesion?Boulder,Col.: Westview, 2001

SCHNEIDER, M.; BUCKLEY, J. What do parents want from schools? evidence from the Intemet. Educational Evaluation and Policy Analysis, Washington, DC, v. 24, n. 2, p. 133-144, 2002.

VAN ZANTEN, A. Fabrication et effets de la ségrégation scolaire. In: Paugam, S. (Dir.). L'exclusion: l'état des savoirs. Paris: La Découverte, 1996.

VAN ZANTEN, A. L'école de la périphérie: scolarité et ségrégation en banlieue. Paris: PUF, 2001.

WITTE, J. Educational choice: a deep divid. In: Prost, A. et al. Espaços de educação: tempos de formação. Lisboa: Fundação Calouste Gulbenkian, 2001.

WHITTY, G. Making sense of education policy. London: Paul Chapman, 2002.

WHITTY, G.; POWER, S.; HALPIN, D. Devolution and choice in education: the school, the state and the market. Buckingham: Open University, 1998.

ZACHARY, M.-D.; VANDENBERGHE, V. L'école et son environnement: pressions concumentielles et stratégies de positionnement. In: MAROY, C. (Dir.). L'enseignementsecondaireetsesenseignants Bruxelles: De Boeck, 2002. 